\title{
Commentary: Evaluation of Models of Parkinson's Disease
}

\author{
Pollyana C. Leal ${ }^{1}$, Lívia C. R. F. Lins ${ }^{1}$, Auderlan M. de Gois ${ }^{1}$, Murilo Marchioro ${ }^{1}$ and \\ José R. Santos ${ }^{2 *}$ \\ ${ }^{1}$ Department of Physiology, Federal University of Sergipe, São Cristóvão, Brazil, ${ }^{2}$ Behavioral and Evolutionary Neurobiology \\ Laboratory, Department of Biosciences, Federal University of Sergipe, Itabaiana, Brazil
}

Keywords: MPTP, 6-OHDA, reserpine, serotonin, neurodegeneration, Parkinson disease

\section{A commentary on}

Evaluation of Models of Parkinson's Disease

by Jagmag, S. A., Tripathi, N., Shukla, S. D., Maiti, S., and Khurana, S. (2016). Front. Neurosci. 9:503. doi: 10.3389/fnins.2015.00503

In the recently published review article by Jagmag et al. (2016), some currently available neurotoxin based and genetic models of Parkinson's disease (PD) were described, highlighting the advantages and disadvantages of preclinical models use to knowledge of PD. The aim of this commentary is to shed light and to make a reflection on some fundamental issues involving the pathophysiology of $\mathrm{PD}$ and additionally bring to the discussion the animal model of PD based on the administration

OPEN ACCESS

Edited by:

Mark R. Cookson, National Institutes of Health, USA

Reviewed by:

Fredric P. Manfredsson, Michigan State University, USA Juan Segura-Aguilar,

University of Chile, Chile

*Correspondence:

José R. Santos joseronaldosantos@gmail.com

Specialty section: This article was submitted to

Neurodegeneration, a section of the journal Frontiers in Neuroscience

Received: 17 April 2016 Accepted: 07 June 2016

Published: 21 June 2016

Citation:

Leal PC, Lins LCRF, de Gois AM, Marchioro M and Santos JR (2016) Commentary: Evaluation of Models of Parkinson's Disease.

Front. Neurosci. 10:283.

doi: 10.3389/fnins.2016.00283 of reserpine (RES).

The pathological hallmark of PD involves the progressive loss of neurons in the substantia nigra pars compacta (SNpc) (Politis and Niccolini, 2015). However, a large body of evidences implies that the PD pathology is a multisystemic degenerative process that involves other neurotransmitters such as serotonin (5-HT) and norepinephrine (NE) (Deusser et al., 2015; Liu et al., 2015; Politis and Niccolini, 2015). It has been demonstrated that the serotonergic system may be the most critical neurochemical system involved in the pathology of PD, after the dopaminergic system (Huot and Fox, 2013; Liguori et al., 2015). Changes in serotonin levels may be a contributing factor to PD symptomatology, in particular, non-motor disturbances (Loane et al., 2013). Patients with PD show loss of serotonergic neurons in the brainstem raphe nuclei (Braak et al., 2003) and reduced expression of tryptophan hydroxylase type 2 (TPH2) in the median raphe nucleus (MnR) (Kovacs et al., 2003). According to Braak staging of PD pathology, serotonergic cell loss in the raphe nuclei is evident prior to nigrostriatal dopaminergic degeneration. Interestingly, the pattern of serotonergic loss also seems to be different from that observed in the dopaminergic system (Politis and Loane, 2011). Additionally, other neuronal systems, including noradrenergic locus coeruleus, are also affected in PD (see review in Jellinger, 1999) and they have been linked to non-motor symptoms of PD as well. Thereby, these evidences of alterations in the raphe nuclei and catecholaminergic nuclei highlight the importance of looking beyond the nigrostriatal system in the PD study, in order to elucidate the underlying mechanisms of deficits of other neurotransmitter systems in the physiopathology of $\mathrm{PD}$ and provide useful information for the development of therapeutic strategies for this disease.

In the paper, Jagmag et al. (2016) highlight toxins widely used as animal models of PD. The toxin 1-methyl-4-phenylpyridinium (MPP+), active metabolite of MPTP, is taken up into dopaminergic terminals by the dopamine transporter (DAT) showing the high affinity for dopaminergic vesicles (Tipton and Singer, 1993; Dauer and Przedborski, 2003). According Andrew et al. (1993), 6-hydroxidopamine (6-OHDA) is elevated in the urine and striatum of L-DOPA treated PD patients, suggesting that 6-OHDA may be an endogenous neurotoxin. This toxin is 
taken up into dopaminergic terminals by DAT as well as taken up to noradrenergic terminals by the noradrenergic transporter (NAT). However, a lot of studies using 6-OHDA model given an inhibitor of NAT as a pretreatment, in order to protect noradrenergic terminal from 6-OHDA toxicity, precluding the possibility of $\mathrm{PD}$ symptomatology analysis as observed in $\mathrm{PD}$ patients. Pesticide-induced model, particularly rotenone and paraquat, have substantial challenges of replicability due the high mortality observed in rats. In addition, these pesticides induce selective degeneration of dopaminergic neurons as illustrated in Figure 1 .

Jagmag and colleagues did not regard the animal model of PD induced by Reserpine (RES). Reserpine model was one of the first models to investigate the pathophysiology and to demonstrate the therapeutic efficacy of L-DOPA, which remains the goldstandard treatment for PD (Carlsson et al., 1957). However, in the 1980s, this toxin became underused due the lack of selectivity for dopamine was considered a failure of the model. The RES is an ester alkaloid derived from Rauwolfia species root that induces symptoms, neurochemical and pharmacological alterations in humans (May and Voegele, 1956) and animals (Fernandes et al., 2012; Santos et al., 2013; Leão et al., 2015) similar to those seen in PD patients. It is an inhibitor of vesicular monoamine transporters (VMAT) as presented in Figure 1. These transporters play an essential role in the presynaptic neurotransmission control and in the regulation of cytoplasmic levels of monoamines. The inhibition of VMAT by reserpine results in a loss of storage capacity of monoamines in synaptic vesicles, causing depletion of brain and peripheral monoamines (Dopamine, NE and 5-HT) leading to oxidative stress (Vergo et al., 2007). Depletion of monoamines, especially of dopamine, and oxidative stress are important features of pathophysiology of PD (Miller and O'Callaghan, 2015). Reserpine is also able to induce motor and non-motor deficits in rodents, such as oral dyskinesia, muscle rigidity (Colpaert, 1987; Neisewander et al., 1994; Fernandes et al., 2012), recognition memory deficits (Santos et al., 2013; Sarmento et al., 2015), anxiety and depressive-like behavior (Santos et al., 2013; AntkiewiczMichaluk et al., 2014), sleep abnormalities (Chen and Marsh, 2014) and gastrointestinal dysfunction such as gastric dysmotility

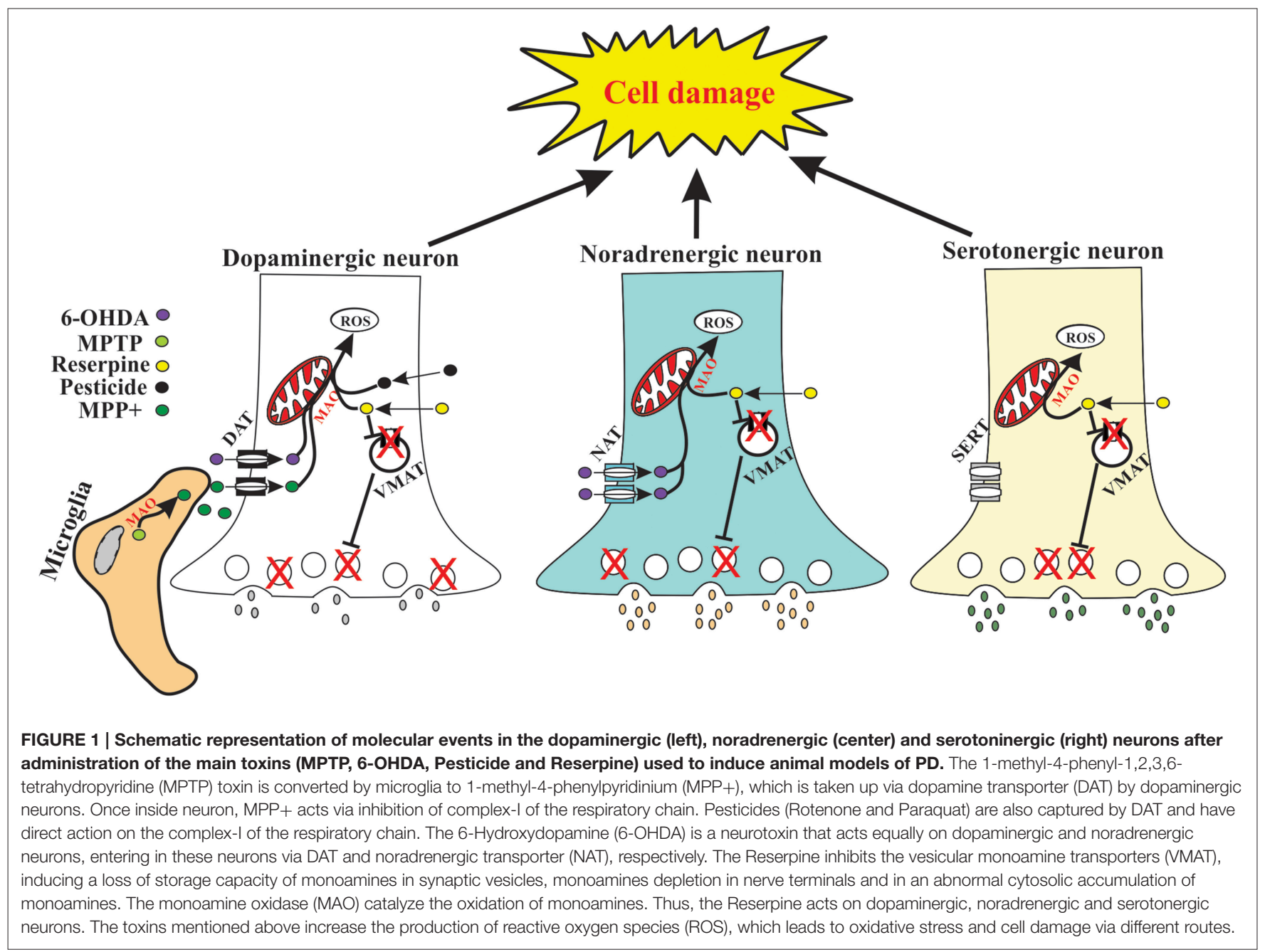


and constipation (Pellegrini et al., 2015). Thus, the reserpine model is a good mimic of the disease biochemistry and an important model of choice for early preclinical stages of drug discovery programmes.

Our research group has proposed that repeated administration of low doses of reserpine can mimic the progressive nature of PD (Santos et al., 2013). In this model, the animals showed cognitive and emotional deficits in the early stages, even before the onset of motor abnormalities. The non-motor symptoms have been associated mainly to impairments in the serotonergic and noradrenergic pathways. The reserpine model has advantages and disadvantages like others animal models of PD. The main advantage of this model is its ability to produce symptoms similar to those observed in the early stages of PD, may be due to monoamines loss (Dopamine, NE and 5-HT). However, the underlying mechanisms of reserpine toxic effects on monoaminergic neurons are not completely understood. We believe that no single PD model is currently available; on the

\section{REFERENCES}

Andrew, R., Watson, D. G., Best, S. A., Midgley, J. M., Wenlong, H., and Petty, R. K. H. (1993). The determination of hydroxydopamines and other trace amines in the urine of Parkinsonian patients and normal controls. Neurochem. Res. 18, 1175-1177. doi: 10.1007/BF00978370

Antkiewicz-Michaluk, L., Wąsik, A., Możdżeń, E., Romańska, I., and Michaluk, J. (2014). Antidepressant-like effect of tetrahydroisoquinoline amines in the animal model of depressive disorder induced by repeated administration of a low dose of reserpine: behavioral and neurochemical studies in the rat. Neurotox. Res. 26, 85-98. doi: 10.1007/s12640-0139454-8

Braak, H., Del Tredici, K., Rüb, U., De Vos, R. A., Jansen Steur, E. N., and Braak, E. (2003). Staging of brain pathology related to sporadic Parkinson's disease. Neurobiol. Aging 24, 197-211. doi: 10.1016/S0197-4580(02)00065-9

Carlsson, A., Lindqvist, M., and Magnusson, T. (1957). 3,4Dihydroxyphenylalanine and 5-hydroxytryptophan as reserpine antagonists. Nature 180:1200. doi: 10.1038/1801200a0

Chen, J. J., and Marsh, L. (2014). Anxiety in Parkinson's disease: identification and management. Ther. Adv. Neurol. Disord. 7, 52-59. doi: $10.1177 / 1756285613495723$

Colpaert, F. C. (1987). Pharmacological characteristics of tremor, rigidity and hypokinesia induced by reserpine in rat. Neuropharmacology 9, 1431-1440. doi: 10.1016/0028-3908(87)90110-9

Dauer, W., and Przedborski, S. (2003). Parkinson's Disease: mechanisms and models. Neuron 39, 889-909. doi: 10.1016/S0896-6273(03)00568-3

Deusser, J., Schmidt, S., Ettle, B., Plötz, S., Huber, S., Müller, C. P., et al. (2015). Serotonergic dysfunction in the A53T alpha-synuclein mouse model of Parkinson's disease. J. Neurochem. 3, 589-597. doi: 10.1111/jnc. 13253

Fernandes, V. S., Santos, J. R., Leão, A. H. F. F., Medeiros, A. M., Melo, T. G., Izídio, G. S., et al. (2012). Repeated treatment with a low dose of reserpine as a progressive model of Parkinson's disease. Behav. Brain Res. 231, 154-163. doi: 10.1016/j.bbr.2012.03.008

Huot, P., and Fox, S. H. (2013). The serotonergic system in motor and nonmotor manifestations of Parkinson's disease. Exp. Brain Res. 230, 463-476. doi: 10.1007/s00221-013-3621-2

Jagmag, S. A., Tripathi, N., Shukla, S. D., Maiti, S., and Khurana, S. (2016). Evaluation of models of Parkinson's disease. Front. Neurosci. 9:503. doi: 10.3389/fnins.2015.00503

Jellinger, K. A. (1999). Post mortem studies in Parkinson's disease - is it possible to detect brain areas for specific symptoms? J. Neural Transm. Suppl. 56, 1-29. doi: 10.1007/978-3-7091-6360-3_1 other hand, there are distinct models that allow us to investigate specific mechanisms of $\mathrm{PD}$, since different mechanisms lead to neuronal cell death in PD and parkinsonian patients exhibit heterogeneous non-motor and motor symptoms.

\section{AUTHOR CONTRIBUTIONS}

All authors participated in the preparation and discussion of the commentary. Designed and organized the illustration: AG.

\section{ACKNOWLEDGMENTS}

This research was supported by fellowships from Conselho Nacional de Desenvolvimento Científico e Tecnológico (CNPq), Coordenação de Aperfeiçoamento de Pessoal de Nível Superior (CAPES), Fundação de Apoio à Pesquisa e à Inovação Tecnológica do Estado de Sergipe (FAPITEC) and Pró-reitoria de Pesquisa da Universidade Federal de Sergipe (POSGRAP/UFS).

Kovacs, G. G., Klöppel, S., Fischer, I., Dorner, S., Linderck-Pozza, E., Birner, P., et al. (2003). Nucleus-specific alteration of raphe neurons in human neurodegenerative disorders. Neuroreport 14, 73-76. doi: 10.1097/01.wnr.0000050301.92401.0c

Leão, A. H., Sarmento-Silva, A. J., Santos, J. R., Ribeiro, A. M., and Silva, R. H. (2015). Molecular, neurochemical, and behavioral hallmarks of reserpine as a model for Parkinson's disease: new perspectives to a long-standing model. Brain Pathol. 25, 377-390. doi: 10.1111/bpa.12253

Liguori, C., Pierantozzi, M., Olivola, E., Mercuri, N. B., and Stefani, A. (2015). Commentary: clinical correlates of raphe serotonergic dysfunction in early Parkinson's disease. Front. Neurol. 21:261. doi: 10.3389/fneur.2015. 00261

Liu, K. C., Li, J. Y., Tan, H. H., Du, C. X., Xie, W., Zhang, Y. M., et al. (2015). Serotonine receptors in the dorsal hippocampus regulate depressive like behavior in unilateral 6-hydroxydopamine lesioned Parkinson's rats. Neuropharmacology 95, 290-298. doi: 10.1016/j.neuropharm.2015. 03.031

Loane, C., Wu, K., Bain, P., Brooks, D. J., Piccini, P., and Politis, M. (2013). Serotonergic loss in motor circuitries correlates with severity of action-postural tremor in PD. Neurology 80, 1850-1855. doi: 10.1212/WNL.0b013e318292a31d

May, R. H., and Voegele, G. E. (1956). Parkinsonian reactions following chlorpromazine and reserpine. AMA Arch. Neurol. Psychiatry 75, 522-524. doi: 10.1001/archneurpsyc.1956.02330230072008

Miller, D. B., and O'Callaghan, J. P. (2015). Biomarkers of Parkinson's disease: present and future. Metabolism 64, S40-S46. doi: 10.1016/j.metabol.2014.10.030

Neisewander, J. L., Castañeda, E., and Davis, D. A. (1994). Dose-dependent differences in the development of reserpine-induced oral dyskinesia in rats: support for a model of tardive dyskinesia. Psychopharmacology 116, 79-84.

Pellegrini, C., Antonioli, L., Colucci, R., Ballabeni, V., Barocelli, E., Bernardini, N., et al. (2015). Gastric motor dysfunctions in Parkinson's disease: current pre-clinical evidence. Parkinsonism Relat. Disord. 21, 1407-1414. doi: 10.1016/j.parkreldis.2015.10.011

Politis, M., and Loane, C. (2011). Serotonergic dysfunction in Parkinson's disease and its relevance to disability. Sci. World J. 11, 1726-1734. doi: $10.1100 / 2011 / 172893$

Politis, N., and Niccolini, F. (2015). Serotonin in Parkinson's disease. Behav. Brain Res. 15, 136-145. doi: 10.1016/j.bbr.2014.07.037

Santos, J. R., Cunha, J. A. S., Dierschnabel, A. L., Campêlo, C. L. C., Leão, A. H. F. F., Silva, A. F., et al. (2013). Cognitive, motor and tyrosine hydroxylase temporal impairment in a model of parkinsonism induced by reserpine. Behav. Brain Res. 253, 68-77. doi: 10.1016/j.bbr.2013. 06.031 
Sarmento, A. J., Lima, R. H., Cabral, A., Meurer, Y., Ribeiro, A. M., and Silva, R. H. (2015). Alpha-tocopherol counteracts cognitive and motor deficits induced by repeated treatment with reserpine. Biochem. Pharmacol. 04, 1-6. doi: 10.4172/2167-0501.1000153

Tipton, K. F., and Singer, T. P. (1993). Advances in our understanding of the mechanisms of the neurotoxicity of MPTP and related compounds. J. Neurochem. 61, 1191-1206.

Vergo, S., Johansen, J. L., Leist, M., and Lotharius, J. (2007). Vesicular monoamine transporter 2 regulates the sensitivity of rat dopaminergic neurons to disturbed cytosolic dopamine levels. Brain Res. 1185, 18-32. doi: 10.1016/j.brainres.2007.09.028
Conflict of Interest Statement: The authors declare that the research was conducted in the absence of any commercial or financial relationships that could be construed as a potential conflict of interest.

Copyright (®) 2016 Leal, Lins, de Gois, Marchioro and Santos. This is an openaccess article distributed under the terms of the Creative Commons Attribution License (CC BY). The use, distribution or reproduction in other forums is permitted, provided the original author(s) or licensor are credited and that the original publication in this journal is cited, in accordance with accepted academic practice. No use, distribution or reproduction is permitted which does not comply with these terms. 